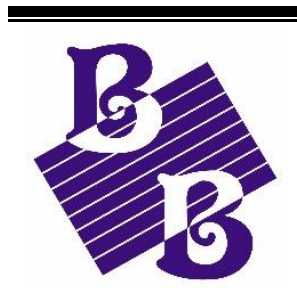

BioBacta

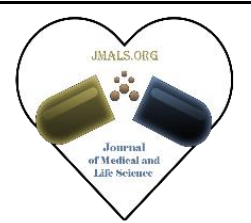

Journal of Medical and Life Science www.jmals.org

\title{
Relationship between vitamin D3 levels and marital status: A random study in females suffering from bone disorders in Al-Najaf province
}

\author{
${ }^{1}$ Hydar Muhsin Khalfa, ${ }^{1}$ Hayder LF Al-Msaid, ${ }^{2}$ Rasha Alsahlanee \\ ${ }^{1}$ Department of biology, faculty of science, university of kufa, Iraq \\ ${ }^{2}$ Biotechnology department, college of science, university of Baghdad, Iraq \\ Corresponding author: Hydar Muhsin Khalfa; Hydarm.jmaiwai@uokufa.edu.i \\ Received: July, 15, 2019; Accepted: Aug., 20, 2019, published: Sep. 1, 2019
}

DOI: 10.21608/jmals.2019.110859

\begin{abstract}
Vitamin D is a fat-soluble steroid hormone. It obtained from foods or by the synthesis in the skin after sunlight exposure (Ultraviolet rays) and converted to the active form in the liver and kidneys. Vitamin D3 is highly affected by hormones of the menstrual cycle. Some evidence also suggests a possible role for vitamin D in the regulation of sexual function. There is no scientific evidence present that shows a relationship between marital status and vitamin D3 levels. The aim of this study is to investigate the correlation between vitamin D3 levels and marital status in females of different age groups in a given population. Methodology: A total of 140 females were randomly selected from the outpatient department in Al-Sader teaching hospital in AlNajaf province Iraq in the period of December 2018 and March 2019. Venous blood (5 ml) was drawn from all subjects. Subjects were classified according to their marital status (single, married) and age groups. Subjects taking vitamin D3 supplementation were discarded from the study. Vitamin D3 and calcium analysis were determined from Human serum using ELISA microtiter plate. Calcium levels $\mathrm{mg} / \mathrm{dl}$ were also determined using serum (Sysmex XP-300 Atomic Hematology Analyzer). Results: The results of this study showed that all females of all age groups suffered from hypovitaminosis D3 due to bone disorders. The levels of vitamin D3 in all age groups single females were significantly $(\mathrm{P}<0.05)$ lower than that in married subjects. Serum calcium levels were statistically significant $(\mathrm{P}<0.05)$ lower in females that are single compared to married females. Conclusion: Females that were single had lower vitamin D3 levels as well as lower serum calcium levels compared to those married. The outcome of this study shows that married females have higher vitamin D3 levels compared to that of single subjects.
\end{abstract}

Keywords: Vitamin D3, bone disorders, marital status, calcium levels 


\section{Introduction}

Vitamin $\mathrm{D}$ is a fat-soluble steroid hormone. It obtained from foods or by the synthesis in the skin after sunlight exposure (Ultraviolet rays) and converted to the active form in the liver and kidneys. Vitamin D3 is highly affected by hormones of the menstrual cycle (Holick et al., 2009). Evidence is increasingly showing that vitamin D deficiency is unrecognized and is a common health problem in various age groups. Vitamin D and calcium are thought of independently possessing anticarcinogenic properties and are effective in protecting against breast cancer. Several experimental studies have indicated that $1,25(\mathrm{OH})$ $2 \mathrm{D}$, which is the biologically active form of vitamin $\mathrm{D}$, can inhibit cellular proliferation and induces differentiation as well as apoptosis, and can inhibit angiogenesis in both normal and malignant breast cells (Pedroza-Tobías et al., 2016). Classification of Vitamin D3 levels are set by the world health organization as follows Deficiency: $<10(\mathrm{ng} / \mathrm{mmol})$ Insufficiency: $\quad 10-30(\mathrm{ng} / \mathrm{mmol}) \quad$ Normal $>30$ (ng/mmol) moreover serum calcium levels are classified as $8.5-10.5 \mathrm{mg} / \mathrm{dL}$ as being a normal value (holick et al., 2006).

Experimental researches have demonstrated that calcium has anti-carcinogenic properties via inhibition of cellular proliferation and induction of mammary cell differentiation. Epidemiological studies which looked at the association between vitamin $\mathrm{D}$ and calcium intake and breast cancer risk have been inconsistent. Moreover several studies have shown that intake of vitamin D or calcium is highly associated with breast cancer risk in both preand postmenopausal females (Takakazu et al., 2010). Due to the inconsistency in findings and the paucity of studies, the World Cancer Research Fund and the American Institute for Cancer Research concluded that the association between intake of vitamin D and calcium and reduction of breast cancer risk was 'limited (Takakazu et al., 2010). Some research evidence also suggests the possible role of vitamin D in regulating sexual function. In particular, recent clinical works have suggested that low vitamin D levels can be associated with the occurrence of sexual disturbances, especially erectile dysfunction, even if not all the studies agree on this point (Canguven et $a l ., 2017)$. There is no scientific evidence present that shows a relationship between marital status and vitamin D3 levels. Also, there is no data available concerning the relationship between vitamin D3 levels and marital status in females in Iraq.

\section{Materials and methods}

2.1 Experimental design: A total of 140 females were randomly selected from the outpatient department in Al-Sader teaching hospital in Al-Najaf province Iraq in the period of December 2018 to March 2019. Subjects taking medication for bone metabolic disorders were not included. The primary complaint was bone symptoms and disorders. Venous blood $(5 \mathrm{ml})$ was drawn from all subjects. Subjects were classified according to their marital status and age group. Subjects taking vitamin D3 supplementation were discarded from the study.

2.2 Vitamin D3 and calcium analysis: Human serum $25 \quad(\mathrm{OH}) 2 \quad \mathrm{D} 3$ 25-hydroxyvitamin D3 (ng/mmol) was determined using ELISA on the microtiter plate. Calcium levels $\mathrm{mg} / \mathrm{dl}$ were also determined using serum (Sysmex XP-300 Atomic Hematology Analyzer).

2.3 Statistical analysis: Data was analyzed by Graphpad prism v6, data was offered with 95\% confidence intervals (CIs) and mean standard deviation (SD). Statistical analysis of variance to compare between groups was tested by one way Anova (F-test). A level of statistical significance was determined by $\mathrm{P}$-value $<0.05$.

\section{Results}

The distribution of subjects in this study varied in all age groups as shown in table 1 below. Subjects were classified according to their age groups and marital status. 
Table 1: The table below shows subjects distribution of all females involved in this study. Subjects were classified into age groups and marital status.

\begin{tabular}{|cccccc|}
\hline Age group & $\begin{array}{c}<\mathbf{2 0} \\
\text { years }\end{array}$ & $\begin{array}{c}\mathbf{2 0 - 3 0} \\
\text { years }\end{array}$ & $\mathbf{3 0 - 4 0}$ years & $\mathbf{4 0 - 5 0}$ years & $\mathbf{5 0}>$ years \\
\hline Married & 10 & 9 & 11 & & 20 \\
\hline Single & 15 & 11 & 19 & 11 & 20 \\
\hline
\end{tabular}

\section{D3 levels and marital status}

The levels of vitamin $\mathrm{d} 3$ varied considerably amongst all age groups. There are noticeable higher levels of vitamin $\mathrm{d} 3$ in married females of all age groups. The $\mathrm{p}$-value for the trend of all married females of all age groups was highly significant $* *(p<0.05)$ compared to single females of all age groups as shown in table 2. The levels of vitamin $\mathrm{d} 3$ in single females of all age groups were lower than those in married females of all age groups. The p-value for the trend of all single females of all age groups was highly significant $*(p<0.05)$ compared to married females of all age groups as shown in table 2 .

Table 2: The table below shows mean vitamin D3 levels in married and single females of all age groups.

Mean D3 levels (ng/mmol) \pm SD

\begin{tabular}{|c|c|c|c|c|c|c|}
\hline Age group & $\begin{array}{c}<20 \\
\text { Years } \\
n=25\end{array}$ & $\begin{array}{c}\text { 20-30 years } \\
n=20\end{array}$ & $\begin{array}{c}\text { 30-40 years } \\
n=30\end{array}$ & $\begin{array}{c}\text { 40-50 years } \\
n=31\end{array}$ & $\begin{array}{c}50>\text { years } \\
n=34\end{array}$ & $\begin{array}{c}P \text { value of } \\
\text { the trend } \\
p<0.05\end{array}$ \\
\hline Married & $10.6 \pm 2.33$ & $13.8 \pm 2.63$ & $10.0 \pm 3.40$ & $11.6 \pm 1.96$ & $9.5 \pm 1.37 *$ & $0.002 * *$ \\
\hline Single & $13.6 \pm 2.33$ & $11.6 \pm 1.36$ & $9.0 \pm 1.41$ & $10.1 \pm 3.3$ & $8.6 \pm 136$ & $0.03 *$ \\
\hline
\end{tabular}




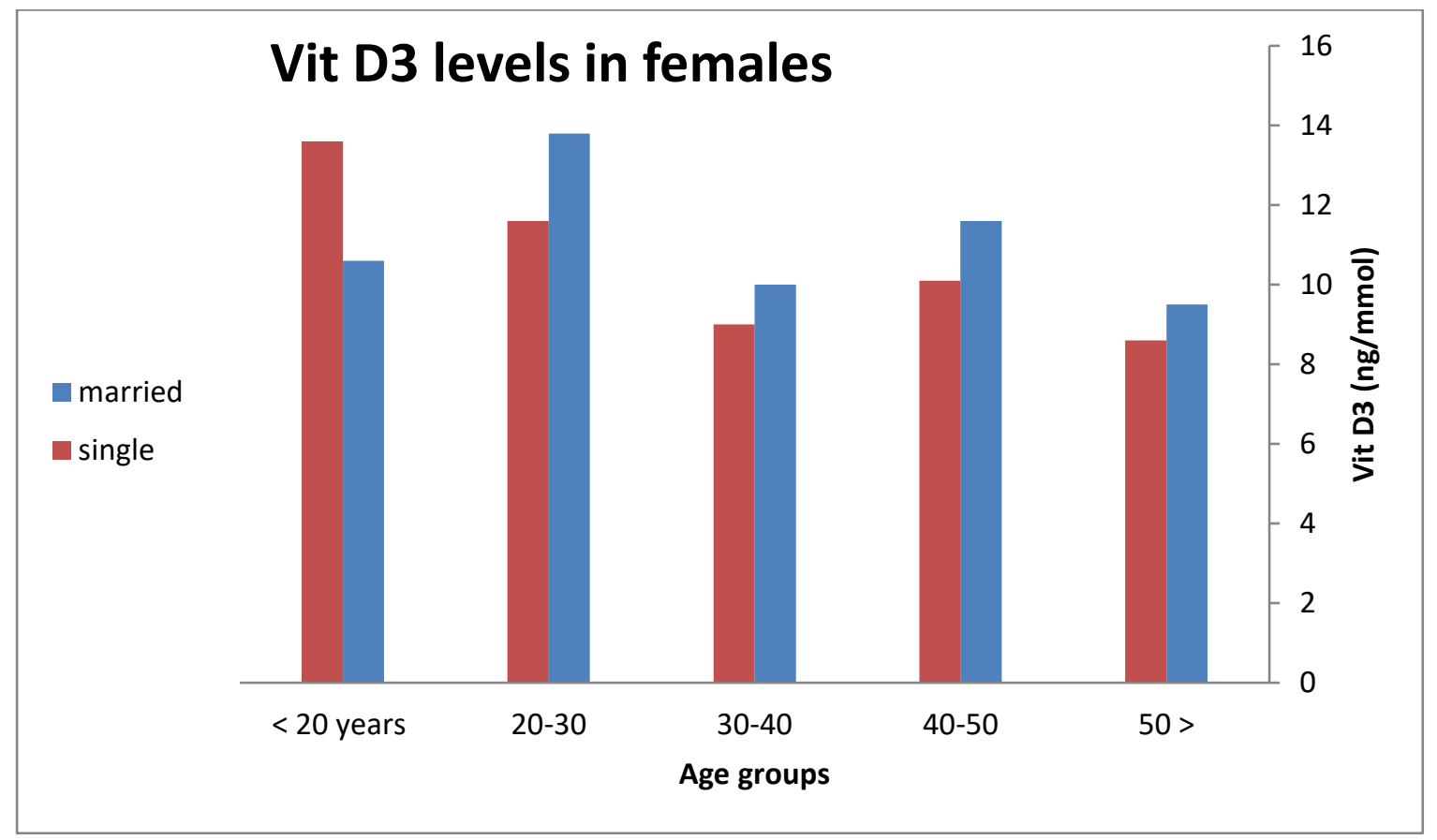

Figure 1: graphical representation of vitamin D3 levels in females according to their marital status and age group.

Table 3: the table below shows the mean calcium levels measured in all female subjects participating in this study.

\begin{tabular}{|c|c|c|c|c|c|c|}
\hline \multirow[b]{2}{*}{ Age group } & \multicolumn{5}{|c|}{ Mean Ca levels (mg/dL) \pm SD } & \multirow[b]{2}{*}{$\begin{array}{l}P \text { value of the } \\
\text { trend } p<0.05\end{array}$} \\
\hline & $\begin{array}{c}<20 \\
\text { Years } \\
n=25\end{array}$ & $\begin{array}{c}\text { 20-30 years } \\
n=20\end{array}$ & $\begin{array}{c}\text { 30-40 years } \\
n=30\end{array}$ & $\begin{array}{c}\text { 40-50 years } \\
n=31\end{array}$ & $\begin{array}{c}50>\text { years } \\
n=34\end{array}$ & \\
\hline Married & $6.0 \pm 1.87$ & $6.0 \pm 0.70$ & $5.1 \pm 1.0$ & $6.9 \pm 2.0$ & $5.8 \pm 1.92$ & $0.827 \mathrm{~ns}$ \\
\hline Single & $6.2 \pm 1.64$ & $3.8 \pm 1.30$ & $3.6 \pm 1.34$ & $6.2 \pm 0.83$ & $4.2 \pm 1.64$ & $0.01 *$ \\
\hline
\end{tabular}




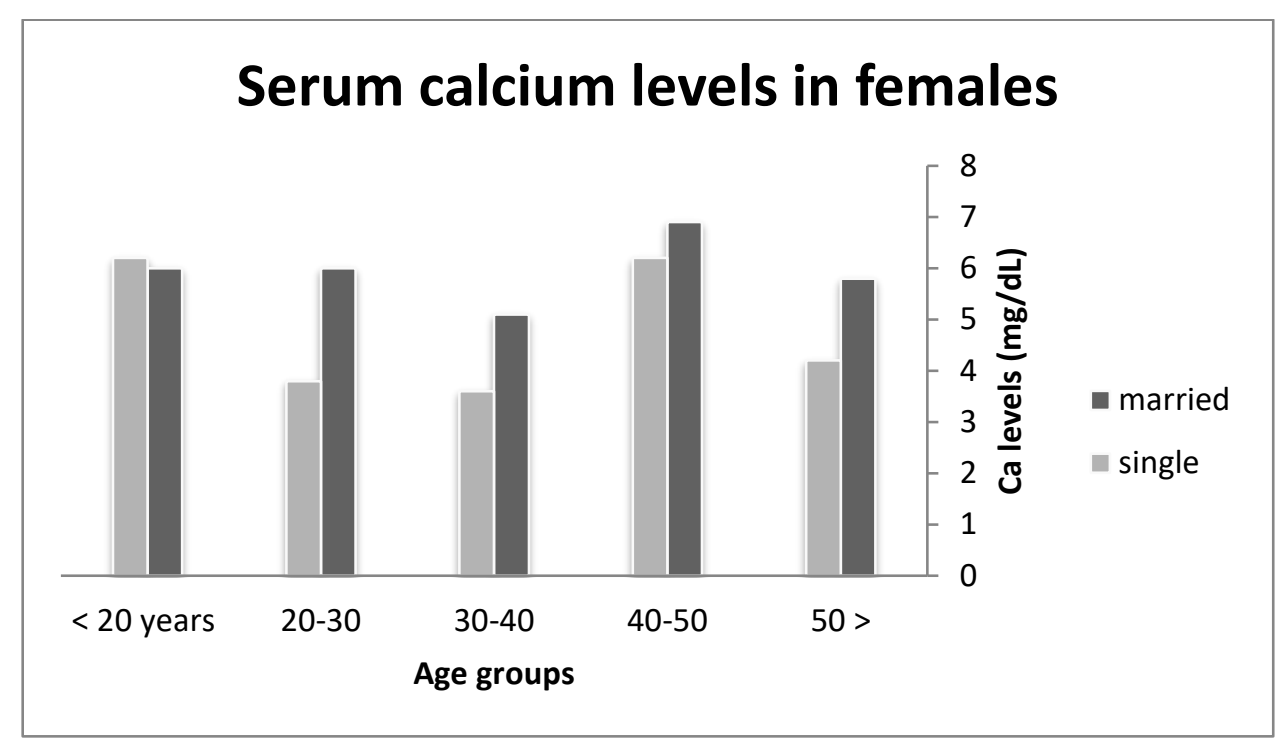

Figure 2: graphical representation of serum calcium levels in females according to their marital status and age group.

The calcium levels in all subjects varied accordingly despite all subjects showed a decreased serum calcium levels however statistical analysis of the trend showed no statistical significance in the trend $\mathrm{p}>0.05$. On the other hand, there was a statistical significance in calcium levels in married females $\mathrm{p}<0.05$.

\section{Discussion}

Vitamin D3 levels can affect several physiological factors in the human body including healthy bone formation and cellular changes. The results of this study showed that being a female you are more like to suffer from bone disorders due to changes in serum vitamin D3 levels. Due to the lacking scientific evidence that interconnects the marital status of females and their hormonal profile including levels of vitamin D3, the current study showed that there is a well-defined relationship between marital status and changes in vitamin D3 levels. A study by Canguven and colleagues (Canguven et al., 2017) showed that vitamin D treatment improved the sexual activity of men. This is closely related to what has been found in this study which is single females are more likely to have deficient vitamin D3 levels due to their lacking sexual activity and inter hormonal play. A study by Caretta and colleagues (Caretta et al., 2016) showed that Hypovitaminosis D is associated with erectile dysfunction in type 2 diabetes this is also concurrent with the results of this current study. Another study by Kidir (Kidir et al., 2015) showed that Sexual dysfunction in a dialysis patients is improved after vitamin D treatment. Despite the lacking scientific evidence, this study showed in a scientific manner that females who are married are less likely to have lower vitamin D3 levels.

\section{$\underline{\text { 5. Conclusion }}$}

A concise conclusion can be drawn out of this study which shows that serum vitamin D3 levels is significantly higher in married females of all age groups compared to single females. No significant relationship is seen in serum calcium levels in both married and single females of all age groups.The study shows that being a married female can influence the levels of vitamin D3 which can be due to hormonal play. 


\section{$\underline{\text { References }}$}

1. McCarty DE, Reddy A, Keigley Q, Kim PY, Cohen S, Marino AA. Nonspecific pain is a marker for hypovitaminosis $\mathrm{D}$ in patients undergoing evaluation for sleep disorders: a pilot study. Nature and science of sleep. 2013;5:37.

2. Pedroza-Tobías, A., Hernández-Barrera, L., López-Olmedo, N., García-Guerra, A., Rodríguez-Ramírez, S., Ramírez-Silva, I. \& Rivera, J. A., 2016. Usual vitamin intakes by Mexican populations. The Journal of Nutrition, 146(9), 1866S-1873S.

3. Holick, M.F., 2009. Vitamin D status: measurement, interpretation, and clinical application. Annals of epidemiology, 19(2), pp.73-78.

4. Holick, M.F., 2007. Vitamin D deficiency. New England Journal of Medicine,357(3), pp.266281.

5. Hovsepian S, Amini M, Aminorroaya A, Amini P, Iraj B. Prevalence of vitamin D deficiency among adult population of Isfahan City, Iran. Journal of Health, Population and Nutrition. 2011 Apr 1:149-55.

6. Caretta N., S. V. de Kreutzenberg, U. Valente et al., "Hypovitaminosis D is associated with erectile dysfunction in type 2 diabetes," Endocrine, vol. 53, no. 3, pp. 831-838, 2016.

7. Barassi A., R. Pezzilli, G. M. Colpi, M. M. Corsi Romanelli, and G. V. Melzi d'Eril, "Vitamin D and erectile dysfunction,"The Journal of Sexual Medicine, vol. 11, no. 11, pp. 2792-2800, 2014.
8. Farag Y. M., E. Guallar, D. Zhao et al., "Vitamin D deficiency is independently associated with greater prevalence of erectile dysfunction: the National Health and Nutrition Examination Survey (NHANES) 2001-2004," Atherosclerosis, vol. 252, pp. 61-67, 2016.

9. Kidir V., A. Altuntas, S. Inal, A. Akpinar, H. Orhan, and M. T. Sezer, "Sexual dysfunction in dialysis patients: does vitamin $\mathrm{D}$ deficiency have a role?," International Journal of Clinical and Experimental Medicine, vol. 8, no. 12, pp. 22491-22496, 2015.

10. Bellastella G., M. I. Maiorino, L. Olita et al., "Vitamin D deficiency in type 2 diabetic patients with hypogonadism," The Journal of Sexual Medicine, vol. 11, no. 2, pp. 536-542, 2014.

11. Canguven O., R. A. Talib, W. El Ansari, D. J. Yassin, and A. Al Naimi, "Vitamin D treatment improves levels of sexual hormones, metabolic parameters and erectile function in middle-aged vitamin D deficient men," The Aging Male, vol. 20, no. 1, pp. 9-16, 2017.

12. Takakazu Kawase,1 Keitaro Matsuo,1,2,6 Takeshi Suzuki,3 Kaoru Hirose, Satoyo Hosono,1 Miki Watanabe,1 Masaki Inagaki,4 Hiroji Iwata,5 Hideo Tanaka1,2 and Kazuo Tajima (2010). Association between vitamin D and calcium intake and breast cancer risk according to menopausal status and receptor status in Japan. Cancer Sci vol. 101 no.5 12341240. 